ISSN1027-5495. Functional Materials, 23, No.3 (2016), p. 404-407

doi:http://dx.doi.org/10.15407/fm23.03.404

(C) 2016 - STC “Institute for Single Crystals"

\title{
Fabrication and electrical characteristics of nano black phosphorus thin film transistor
}

\author{
Wang Lie-long \\ School of Mechanical and Electrical Engineering, Chizhou University \\ Chizhou 247000, China \\ Department of Physics, Zhejiang University, Hangzhou 310027, China
}

Received January 27, 2016

\begin{abstract}
This text introduced a method to fabricate black phosphorus(BP) nanosheet field effect transistor(FET). The X ray diffraction analysis, scanning electron microscopy, and FET performance of the black phosphorus products were analyzed, and the output characteristic curves and the transfer characteristic curves were obtained. When BP's thickness was $14 \mathrm{~nm}$, the hole mobility was $244 \mathrm{~cm}^{2} / \mathrm{Vs}$ and on/off ratio was $\sim 10^{3}$. The result shows that black phosphorus nanosheet field effect transistor has good on/off ratio and hole mobility. It will lay an important foundation for future optoelectronic devices as an alternative material.
\end{abstract}

Keywords: black phosphorus, production process, morphology, function of FET

Методами дифракционного рентгеновского анализа и сканирующей электронной микроскопии исследуются нанокристаллы, полученные из природного черного фросфора. Определены подвижность электронов $\left(244 \mathrm{~cm}^{2} / \mathrm{Vs}\right)$ и коэффициент переключения тока $\left(\sim 10^{3}\right)$. Результаты показывают, что наноматериалы на основе черного фосфора могут найти применение в оптоэлектронных устройствах как альтернативный материал существующим.

\footnotetext{
Исследование эксплуатационных характеристик черного фосфора FET и его применение. Ван Ли-лонг.

Методами дифракційного рентгенівського аналізу і скануючої електронної мікроскопії досліджуються нанокристали, отримані з природного чорного фосфору. Визначено рухливість електронів $\left(244 \mathrm{~cm}^{2} / \mathrm{Vs}\right)$ і коефіціент перемикання струму $\left(\sim 10^{3}\right)$. Результати показують, що наноматеріали на основі чорного фоссрору можуть знайти застосування в оптоелектронних пристроях як альтернативний матеріал існуючим .
}

\section{Introduction}

Two-dimensional materials, like graphene, $\mathrm{BN}$ and transitional metal dichalcogenides $\mathrm{M}_{\mathrm{O}} \mathrm{S}_{2}$, show excellent physical and chemical properties. These materials currently get the attention of scholars [1-5]. As we all know, graphene has high electron mobility, high thermal conductivity and excellent properties in Hall effect at room temperature, but it lacks the band gap, with smaller current on/off ratio. So, it is not widely used in practical applications. Another two dimensional material $\mathrm{M}_{\mathrm{O}} \mathrm{S}_{2}$, although it has a direct band gap about $1.8 \mathrm{eV}$ in monolayer and a relatively high switching ratio, its carrier mobility is much lower than that of graphene. Therefore, it has become an important subject to find the materials with suitable band gap and high carrier mobility [6-11]. Recently, Professor Zhang Yuanbo's research group in the Physics Department of Fudan University, successfully prepared Black P field effect transistor device. This new two-dimensional materials also has a direct band gap and high hole mobility. It can overcome the shortcomings of 
graphene as a good substitute material [12]. In the 1950s, people have begun to study black phosphorus. Black phosphorus is an allotrope of phosphorus, it has a layered structure with convalent bonds in inner layer's atoms and the van der Waals force combined between layers. Inspired by the study of graphene, it is a very interesting topic to study the preparation, exfoliation technology and the properties of the single layer or multilayer BP [13-15]. In this paper, we mainly study the black phosphorus single crystal FET prepared by mechanical exfoliation method. BP nanosheet was attached to the $\mathrm{SiO}_{2} \backslash \mathrm{P}^{++} \mathrm{Si}$ substrate and the output characteristic curve, transfer characteristic curve, carrier mobility, current on/off ratio and other parameters were calculated and discussed. The field effect transistor based on BP nano materials is expected to provide a new choice for the development of integrated circuit technology in the future.

\section{Experimental}

The red phosphorus, tin and tin tetraiodide were mixed according to a certain mass ratio(1 6:40 50:1 2). They were put into a quartz tube with $9 \mathrm{~cm}$ in length and $1.2 \mathrm{~cm}$ in diameter. The quartz tube was vacuumized and sealed. The temperature was set as follows, first it was increased from room temperature to $863 \mathrm{~K}$ and kept for $2 \mathrm{~h}$, then, the temperature was dropped to $758 \mathrm{~K}$ and kept for $2 \mathrm{~h}$. Finally, it was cooled down to room temperature and black phosphate single crystal was obtained (figure 1).

Using mechanical exfoliation method, the black phosphorus nanosheet was attached to the wafer covered with $300 \mathrm{~nm} \mathrm{SiO}$. First of all, bulk black phosphorus crystal was attached to the tape after hand stripping 3 to 4 times and eventually transferred to the substrate $\left(8 \mathrm{~mm} \times 8 \mathrm{~mm} \mathrm{SiO}_{2} \mid \mathrm{P}^{++} \mathrm{Si}\right)$. Figure 2 shows the $\mathrm{SiO}_{2} \mathrm{IP}^{++} \mathrm{Si}$ substrate was covered with a $\mathrm{BP}$ nanosheet. Using an optical microscope (Olymp $\mathrm{B} \times 51 \mathrm{M}), \mathrm{BP}$ nanosheet's morphology was observed. According to its color, the approximate thickness of BP could be estimated. From Figure 2, we can see the BP film attached to the $\mathrm{SiO}_{2} \mid \mathrm{P}^{++} \mathrm{Si}$ substrate has a thickness of about $10 \mathrm{~nm}$ and a length of about $30 \mu \mathrm{m}$ around, the width of $\mathrm{BP}$ is about $10 \mathrm{~nm}$. Figure 3 shows the crystal structure of the sample, which was analyzed by X-ray diffraction (XRD).

To fabricate BP FET, the copper grid (1000 meshes, $3.05 \mu \mathrm{m} \times 3.05 \mu \mathrm{m}$ of each mesh) was used to cover BP nanosheet in the area $10 \mu \mathrm{m} \times 30 \mu \mathrm{m}$. Then, the conductive tape and glass fiber were used to be attached with a stainless steel (200 meshes). Finally, they were fixed together with the substrate by using a clamp. The whole

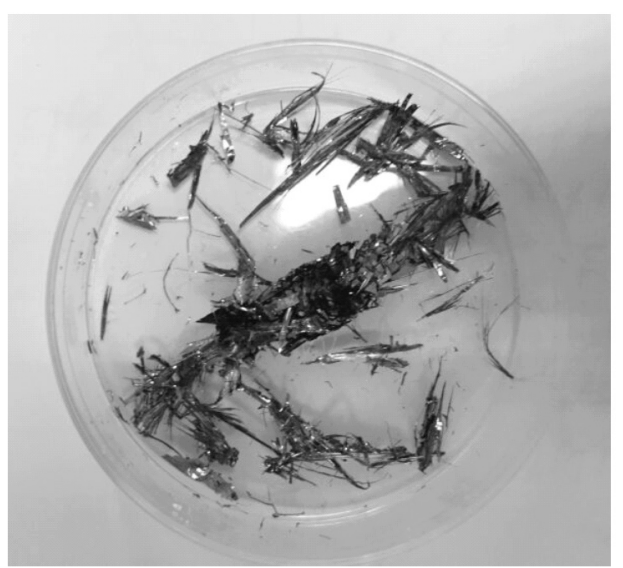

Fig. 1 The black phosphorus crystals in quartz tubes

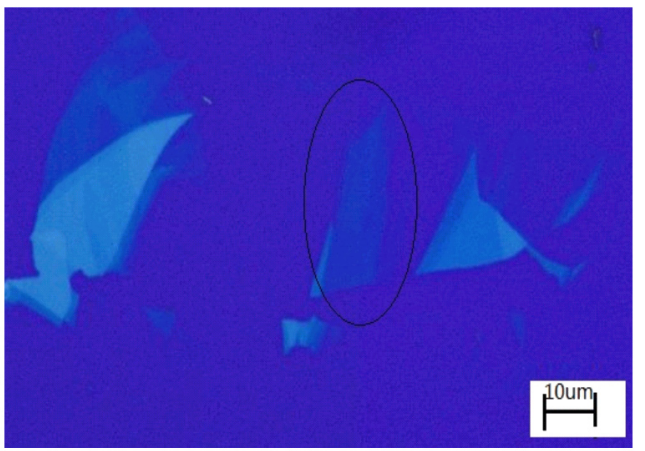

Fig. 2. The OM image of black phosphorus nanophase materials $(\times 1000)$

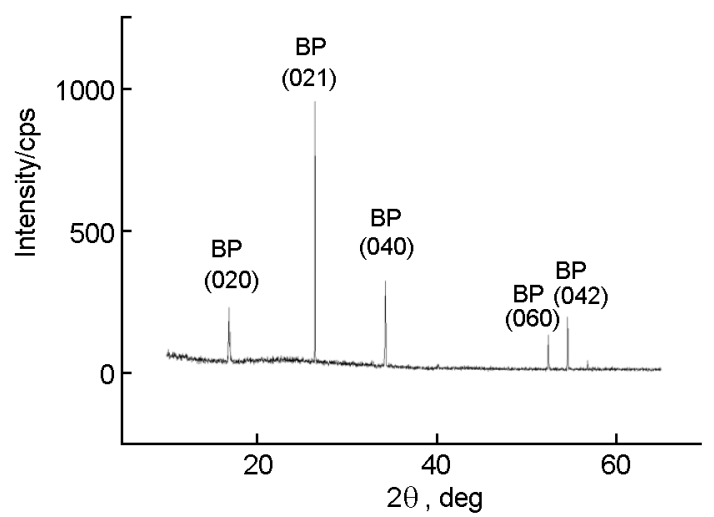

Fig. 3. XRD pattern of black phosphorus crystals

device was put into a magnetron sputtering equipment (FJL 450) for sputtering the electrodes Ti (20nm, below) and Au (80nm, upper). The channel length between drain and source is $6 \mu \mathrm{m}$. Figure 4 shows the SEM image (KYKYEM3200) of the prepared FET. Figure 5 shows its optical image, and figure 6 shows the schematic of BP FET.

\section{Result and discussion}

Fig. 8 shows the output characteristic curve measured according to the test circuit of Fig. 7. 


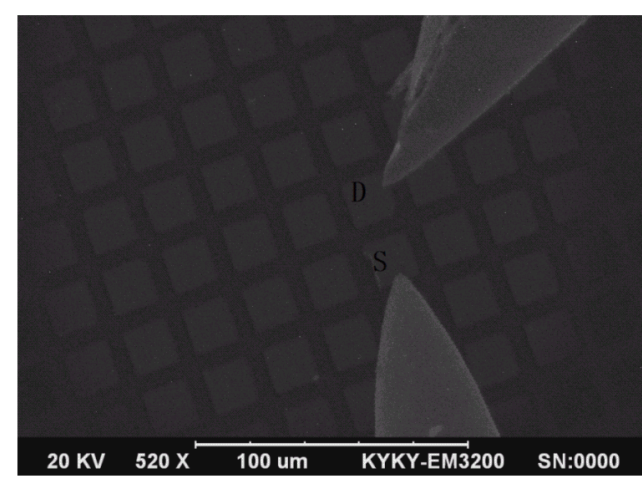

Fig. 4 The SEM image of BP nanophase materials field effect transistor

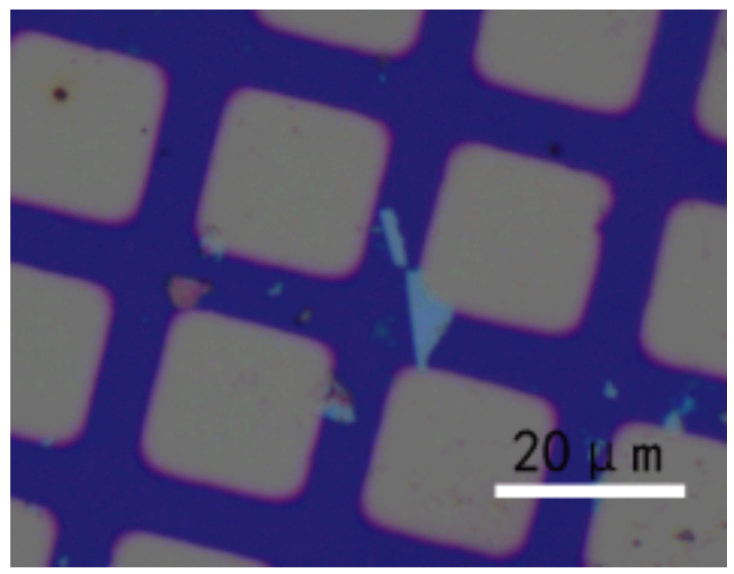

Fig. 5. OM image of BP field effect transistor $(\times 1000)$

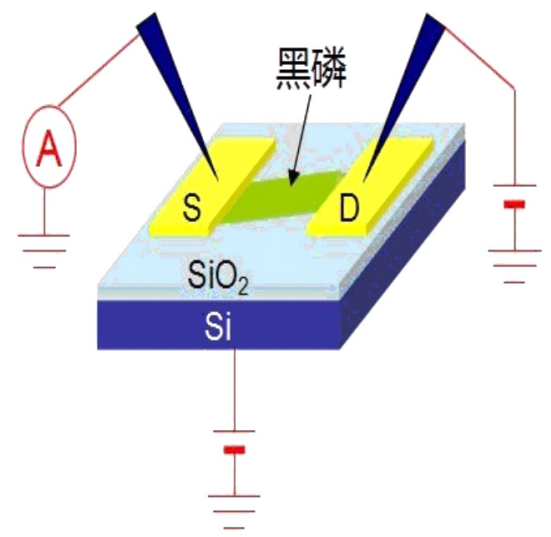

Fig. 6. The schematics of BP field effect transistor

Figure 8 shows that the output characteristic of the device is similar to that of the junction type FET. The current decreases with the increase of $V_{g s}$, which shows that it is $p$-type semiconductor. When $V_{\text {s }}<0 \mathrm{~V}$ and the conduction band of black phosphorus bends downward near the Fermi level, the hole carrier concentration increases. Conversely, when $V_{g s}>0 \mathrm{~V}$, black phosphorus's conduction band curves away from the Fermi level, so the hole carrier concentration decreases.

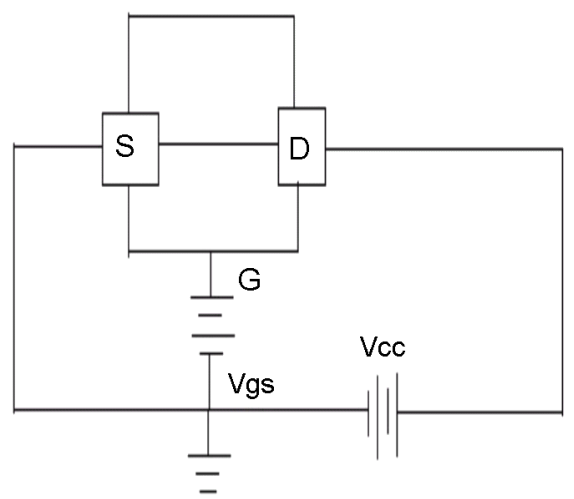

Fig. 7 The diagram of the test circuit

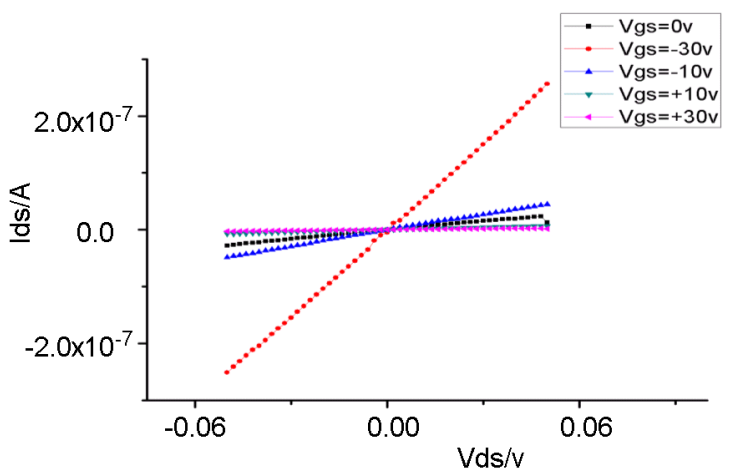

Fig. 8. The output characteristics under different Vgs

The transfer characteristic of the BP field effect tube is shown in Fig. 9, and the device can be judged as a $p$-type semiconductor according to the transfer characteristic curve.

The calculation formula of low-frequency transconductance $g_{m}$ is as follows:

$$
g_{m}=\frac{\Delta I_{d s}}{\Delta V_{g s}}
$$

Taking $V_{d s}=+0.2 V+0.4 V+0.6 V$, the calculated low-frequency transconductance were $19.4 \mathrm{nS}, 27.5 \mathrm{nS}$ and $45.6 \mathrm{nS}$, respectively. This result shows that the $g_{m}$ increases with the increase of $V_{g s}$.

Hole mobility shows the drift velocity of the hole under the unit external electric field. The hole mobility's calculation is shown as follows:

$$
\mu_{e}=\frac{\mathrm{d} I_{d S}}{d V_{g s}} \cdot \frac{L}{C_{o x} \cdot W \cdot V_{d S}}
$$

$I_{d S}$ - source drain current; $\mathrm{V}_{g s}$ - gate voltage; $L, W$ - the length and width of the black phosphorus sample are $10 \mathrm{~nm}$ and $6 \mathrm{~nm}$, $V_{d S}$ - source drain voltage.

$C_{o x}$ - the capacitance of the dielectric layer $\mathrm{SiO}_{2}$ can be calculated by the following formula:

$$
C_{o x}=\frac{\varepsilon_{0} \cdot \varepsilon_{r}}{t}
$$

Functional materials, 23, 3, 2016 


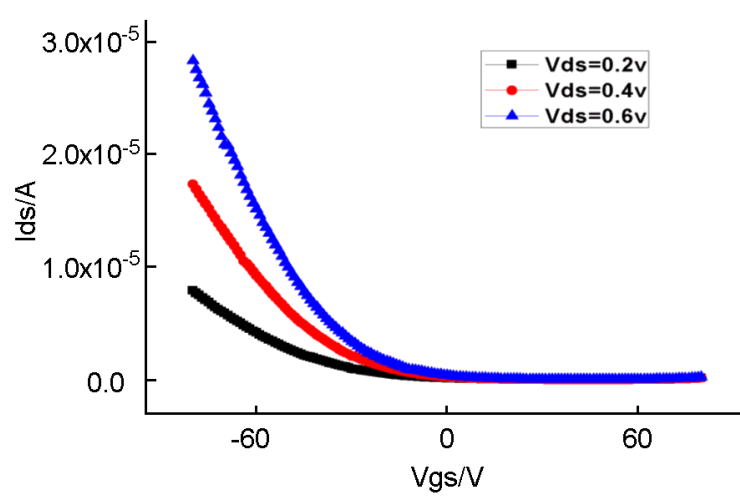

Fig. 9. The transfer characteristics under different Vds

$\varepsilon_{0}$ - vacuum dielectric constant, the value is: $8.854187817 \times 10^{-12} \mathrm{~F} / \mathrm{m} ; \varepsilon_{r}-$ the relative dielectric constant of $\mathrm{SiO}_{2}$, the value is: 3.8 ; $t$ - thickness of $\mathrm{SiO}_{2}$ layer, $300 \mathrm{~nm}$.

The current switching ratio formula is calculated as follows:

$$
i_{\text {on } / \text { off }}=\frac{I_{d s \max }}{I_{d s \min }}
$$

In the formula, $V_{d s}=0.1 v, V_{g s}=0 v$, $I_{d s \max }=1.05 \times 10^{-5} \mathrm{~A}, I_{d s \min }=1.13 \times 10^{-8} \mathrm{~A}$. The calculation results show that the electron mobility of black phosphorus is $244 \mathrm{~cm}^{2} / \mathrm{V} . \mathrm{s}$; the current switch ratio $i_{\text {on/off }}$ is about $\sim 10^{3}$; the thickness is $14 \mathrm{~nm}$.

\section{Conclusions}

This paper introduced a method for preparing black phosphorus crystals and black phosphorus nanosheet. The field effect transistor based on the black phosphorus nanosheet was prepared by using a monolayer or multilayer $\mathrm{BP}$ attached to $\mathrm{SiO}_{2} \mid \mathrm{P}^{++} \mathrm{Si}$ substrate. XRD and SEM are used to analyse the structure and morphology of the samples of BP. BP's output characteristic curve and the transfer characteristic curve can be tested by experiments. When$V_{d s}=0.1 \mathrm{~V}, V_{g s}=0 \mathrm{~V}$, the calculated hole mobility is $\mu_{\mathrm{e}}=244 \mathrm{~cm}^{2} / \mathrm{V} . \mathrm{s}$, the current switching ratio $i_{\text {on } / \text { off }}$ is about $\sim 10^{3}$, and the BP nano material field effect transistor has better hole mobility and current switching ratio. In the future, it is expected to be applied in large scale integrated circuit, and the thickness of BP attached to the $\mathrm{SiO}_{2} \mid \mathrm{P}^{++} \mathrm{Si}$ substrate has an influence on the hole mobility and the current switching ratio. How it influences and what the mechanism is will be further studied.

\section{Acknowledgements}

This work was financially supported by $\mathrm{Na-}$ tional Natural Science Foundation of China (NO.51272232).

\section{References}

1. K.S. Novoselov, A.K. Geim, et al. J. Science, 206, 666, 2006.

2. W. Li, G. Zhang, M. Guo et al., J. Nano Res, 7, 518, 2014.

3. K.N. Duerloo, Y. Li, E.J. Reed, J. Nature. Commun, 5, 42142014.

4. O. Rader, A. Varykhalov, J. Sanchez-Barriga, et al., J. Phys. Rev. Lett, 102, 057602, 2009.

5. V. Barone, J E Peralta, J. Nano Lett, 8, 2210, 2008.

6. Reich E S. J. Nature, 506, 19, 2014.

7. H. Liu, A.T, Neal, Z. Zhu, et al., Acs Nano, 8(4), 4033, 2014.

8. Nihar D. Pradhan, Daniel Rhodes, Simin Feng, et al. Acs Nano, 8(6), 5911, 2014.

9. S. Das, H.Y. Chen, A.V. Penumatcha, et al. Nano Lett., 13(1),100, 2013.

10. S. Das, J. Appenzeller, Rapid Res. Lett., 7(4), 268, 2013.

11. S. Yang, J. Appenzeller, Nano Lett.,9(8), 2973, 2009.

12. The Chinese Powder Industry, Research Molybdenum Powder Research Center 2, 42, 2014.

13. Y. Takao, A. Morita, J. Phys.B, 105, 93, 1981.

14. R.W. Keyes, J. Phys.Rev, 92, 580, 1953.

15. A. Brown, S. Rundqvist, J. Acta Cryst, 19, 684, 4. 